\title{
Three Classes of Inhibitory Amino Acid Terminals in the Cochlear Nucleus of the Guinea Pig
}

\author{
JOSE M. JUIZ, ROBERT H. HELFERT, JOANN M. BONNEAU, ROBERT J. \\ WENTHOLD, AND RICHARD A. ALTSCHULER \\ Kresge Hearing Research Institute, The University of Michigan, Ann Arbor, \\ Michigan 48109-0506 (J.M.J., J.M.B., R.A.A.); Departments of Surgery and Pharmacology, \\ Southern Illinois University School of Medicine, Springfield, Illinois 62794-9230 (R.H.H.); \\ Laboratory of Neurochemistry, National Institute for Deafness and \\ Communication Disorders, NIH, Bethesda, Maryland 20892-4162 (R.J.W.)
}

\begin{abstract}
Electron microscopic postembedding immunocytochemistry was used to analyze and assess the synaptic distribution of glycine (GLY) and $\gamma$-amino butyric acid (GABA) immunoreactivities in the guinea pig cochlear nucleus $(\mathrm{CN})$. Three classes of endings were identified containing immunolabeling for glycine, GABA, or both glycine and GABA (GLY/GABA). All classes were similar in that the terminals contained pleomorphic vesicles and formed symmetric synapses with their postsynaptic targets. A fourth class, which labeled with neither antibody, contained round vesicles and formed asymmetric synapses. Glycine endings predominated in the ventral $\mathrm{CN}$, while GLY/GABA endings were prevalent in the dorsal CN. GABA endings were the least common and smallest in size. Glycine, GLY/GABA, and GABA endings differed in their proportions and patterns of distribution on the different classes of projection neurons in the $\mathrm{CN}$, including spherical bushy, type I stellate/multipolar, and octopus cells in the ventral CN and fusiform cells in the dorsal CN. The vast majority of anatomically-defined, putative inhibitory endings contain GLY, GABA, or both, suggesting that most of the inhibition in the cochlear nucleus is mediated by these three cytochemically and, probably, functionally distinct classes of endings. The results of this study also suggest that a large proportion of the GABA available for inhibition in the CN coexists in terminals with glycine. 1996 Wiley-Liss, Inc.
\end{abstract}

Indexing terms: auditory, immunocytochemistry, GABA, glycine, co-localization

The amino acids glycine (GLY) and $\gamma$-amino butyric acid (GABA) are the major chemical mediators of inhibitory neurotransmission in the central nervous system (Cooper et al., 1985; McGeer et al., 1987), and the cochlear nucleus (CN), which contains the second order neurons of the auditory pathway (reviewed by Lorente de No, 1981; Moore, 1986; Morest, 1993), is no exception. Extensive work from many laboratories has provided evidence that both GABA and GLY are the major neurotransmitters mediating inhibitory activity in the cochlear nucleus (for reviews, see Godfrey et al., 1988; Altschuler et al., 1993; Caspary et al., 1993; Evans and Zhao, 1993; Oertel and Wickesberg, 1993; Potashner et al., 1993). Both GABA and GLY can act via ionotropic receptors and provide rapid inhibitory modulation of the excitatory acoustic signal carried to $\mathrm{CN}$ neurons by auditory nerve fibers. GABA can also act via the metabotropic GABA-B receptor.

The involvement of GABA and GLY in inhibitory neurotransmission in the $C N$ has raised questions regarding their cellular and synaptic localization (Wenthold, 1991). There have been many immunocytochemical studies of GABA, its biosynthetic enzyme (glutamic acid decarboxylase, GAD), and GLY in the CN (Mugnaini, 1985; Mugnaini and Oertel, 1985; Shiraishi et al., 1985; Thompson et al., 1985; Peyret et al., 1986, 1987; Wenthold et al., 1986, 1987; Altschuler et al., 1986a,b, 1993; Adams and Mugnaini, 1987; Moore and Moore, 1987; Roberts and Ribak, 1987; Aoki et al., 1988; Oberdorfer et al., 1988; Carr et al., 1989; Code and Rubel, 1989; Saint Marie et al., 1989, 1991, 1993; Osen et al., 1990; Wenthold and Hunter, 1990; Kolston et al., 1992; Morest, 1993). The light microscopic evalua-

\footnotetext{
Accepted March 25, 1996

Jose M. Juiz's present address is Department of Histology and Institute of Neuroscience, University of Alicante, 03580 Alicante, Spain.

Address reprint requests to Richard A. Altschuler, Kresge Hearing Research Institute, The University of Michigan, 1301 East Ann, Ann Arbor, MI 48109-0506
} 
tions showed abundant immunolabeling for GABA or GAD, and GLY in fibers and terminals throughout the CN neuropil and around most, if not all, neuronal cell bodies in this nucleus. GABA, GAD, or GLY immunolabeling was also shown in populations of neuronal cell bodies in the $\mathrm{CN}$, which are far more numerous in the dorsal CN (DCN) than in the ventral CN (VCN) (Kolston et al., 1992). The labeled cells are likely to be interneurons that give rise to part of the rich system of putative GABAergic or glycinergic synapses in the CN (Wenthold, 1991), although there are also indications that a substantial component originates from projection neurons located extrinsically in other auditory nuclei (Altschuler et al., 1993; Potashner et al., 1993; Saint Marie et al., 1993; Wickesberg and Oertel, 1993).

Ultrastructural evaluation provides a degree of analysis in which GABA and GLY immunolabeling can be resolved to individual synaptic terminals (e.g., Altschuler et al., 1986a, 1993), allowing the opportunity to better characterize the patterns of GABAergic and glycinergic synaptic distribution on individual neurons. Several ultrastructural studies have assessed GAD, GABA, or glycine immunoreactivity at the ultrastructural level in the CN (Mugnaini, 1985; Altschuler et al., 1986a, 1993; Wenthold et al., 1986, 1987; Adams and Mugnaini, 1987; Oberdofer et al., 1988; Saint Marie et al,, 1989). However, few studies have examined and compared the synaptic co-containment of GABA and GLY (Wenthold et al., 1988; Altschuler et al., 1993), and none surveyed the entire CN. Since most neuronal types tested so far in the $\mathrm{CN}$ are inhibited by GABA and GLY (Caspary, 1986; Caspary et al., 1979, 1985, 1993), it is essential to study both transmitters in the same tissue. Rather than being spatially segregated, GABA and GLY immunoreactivities may coexist in some neuronal and terminal populations of the CN (Wenthold et al., 1987; Oberdorfer et al., 1987; Juiz et al., 1989a; Osen et al., 1990; Kolston et al., 1992), as well as in the cerebellum (Ottersen et al., 1988, 1990), superior olivary complex (Helfert et al., 1992), and spinal cord (Triller et al., 1993a,b). Thus, it is important to categorize the different types of GABA/GLY terminals in an ultrastructural evaluation of these amino acid transmitters in the $\mathrm{CN}$ in order to better predict their functional roles.

Therefore, we sought to analyze and compare the synaptic distribution of GABA and GLY immunoreactivities in the CN. To accomplish this goal we have used ultrastructural postembedding immunogold immunocytochemistry on adjacent pairs of ultrathin sections, labeled sequentially to detect GABA or GLY immunoreactivity in the same synaptic structure. The use of the immunogold technique makes it possible to make semiquantitative comparisons of the localization of these amino acids in the different neural compartments in the $\mathrm{CN}$.

\section{MATERIALS AND METHODS}

The care and use of animals in this study was approved and supervised by the University of Michigan Unit on Laboratory Animal Medicine. Eight adult, pigmented guinea pigs (250-350 g) with normal pinna reflexes were used in this study. They were deeply anesthetized with an intraperitoneal injection of sodium pentobarbital $(75 \mathrm{mg} / \mathrm{kg})$ and perfused transcardially with $3 \%$ paraformaldehyde and $0.5 \%$ glutaraldehyde in $0.1 \mathrm{M}$ sodium cacodylate buffer $(\mathrm{pH}$ 7.35). Each animal received 600 to $800 \mathrm{ml}$ of fixative at a rate of 50 to $70 \mathrm{ml} / \mathrm{min}$. The brainstem was removed and immersed in the same fixative for 2 to 4 hours at $4^{\circ} \mathrm{C}$ followed by an overnight wash in cold phosphate-buffered saline (PBS), pH 7.2-7.4.

Transverse sections through the auditory brainstem were obtained at a thickness of $100 \mu \mathrm{m}$ with a Vibratome (Oxford) and postfixed at room temperature for 1 hour ir $0.1 \%$ osmium tetroxide in $0.1 \mathrm{M}$ cacodylate buffer, $\mathrm{pH} 7.35$ Following osmication, the sections were washed in thret. 5 -minute changes of cacodylate buffer, dehydrated in graded ethanols, and flat embedded in epoxy resin (EMbed 812 EMSciences, Fort Washington, PA). After polymerization. subdivisions of the CN were dissected from the sections and glued to blank resin blocks with a cyanoacrylate adhesive (Borden Wonderbond, Bordon, Columbus, OH).

Immunogold immunocytochemistry on ultrathin sections. Ninety-five $\mathrm{nm}$ serial sections were cut with an ultramicrotome (Reichert Ultracut, Vienna, Austria) and mounted on precleaned nickel grids. They were treated with an aqueous $1 \%$ sodium metaperiodate for 15 minutes to remove excess osmium, rinsed in phosphate buffered saline (PBS), and pre-incubated for 1 hour in normal goat serum diluted 1:3 in a solution of $0.3 \%$ Triton X-100 in PBS (PBS-Triton). In a humidified chamber, grids with adjacent. sections were incubated 24 hours at room temperature in antisera against GABA and GLY conjugates, diluted respec. tively $1: 300$ and 1:200 in PBS-Triton. The characteristics and specificity of these antibodies have been reported elsewhere (Wenthold et al., 1986, 1987). After a PBS rinse. the grids were incubated for 2 hours in goat anti-rabbit IgG conjugated to $15 \mathrm{~nm}$ colloidal gold particles (Auroprobe GAR15, Janssen Pharmaceutica, Piscataway, NJ), diluted 1:10 in PBS-Triton. Following distilled water rinses, the sections were counterstained with lead citrate and examined with a JEOL EM-1200 electron microscope equipped with a double grid specimen holder to facilitate the study of serial sections.

Evaluation of immunogold immunolabeling. Synaptic endings, axons, or cell bodies were considered immunolabeled whenever an unequivocally large accumulation of gold particles was evident over these structures. Accumulation of gold particles on tissue areas judged as non-labeled ('background labeling') had at least 3-4 times lower density than labeled terminals, and accumulation was virtually absent from regions of empty resin, which permitted subjective evaluation of immunolabeling.

Quantitative comparisons. Subjective patterns of GABA and GLY immunolabeling were confirmed from electron micrographs by calculating the average density of gold particles on a sample of 175 terminals and glial profiles in the VCN and DCN. Gold particles were visually counted and the perimeter of each profile was traced on a digitizing tablet attached to a video display system and microcomputer [Summagraphic digitizing tablet, Dage-MTI Precision 81 video camera and monitor, ZEOS computer], which calculated the surface area of the profile and density of its gold particles (expressed as number of gold particles $/ \mu \mathrm{m}^{2}$ of profile) with software designed in-house. Statistical comparisons were made by means of ANOVAs with Bonferroni's correction for comparisons among multiple groups.

Immunocytochemical controls. Controls for the specificity of the antibodies included incubation of sections in anti-GABA or anti-GLY conjugate preadsorbed with their respective antigens, which abolished all immunolabeling. Preadsorption of anti-GABA antibodies with GLY conjugates or vice versa had no noticeable effect on the immunolabeling. To evaluate the specificity of the immunogold detection method, ultrathin sections were incubated in PBS-Triton without the primary antibody, followed by the 
secondary antibody labeled with colloidal gold. No immunogold labeling was found in the absence of primary antibody.

\section{RESULTS \\ Synaptic Distribution of GABA and GLY Immunolabeling Reveals Three Classes of Putative Inhibitory Endings in the CN}

An analysis of the patterns of localization of GABA and GLY immunolabeling in synaptic endings of the CN revealed the existence of three different types of labeled endings. One type was characterized by high levels of GLY immunoreactivity (GLY endings). The second type possessed intense GABA immunoreactivity (GABA endings) and the third type contained elevated levels of immunoreactivity for both GLY and GABA (GLY/GABA endings) (Fig. 1). Semiquantitative evaluation of the density of gold particles over profiles of GLY, GABA, and GLY/GABA terminals confirmed these observations (Fig. 2). In GLY endings, immunoreactivity for GLY was 14 times higher than that in glia, while GABA immunolabeling was essentially indistinguishable from glial levels (Fig. 2A). In GABA endings, GABA immunoreactivity was, on average, 12 times higher than in glia (Fig. 2B). In GLY/GABA endings, the average densities of both GLY and GABA immunolabeling were substantially higher than in glia ( 7 and 6 times respectively) but interestingly, only half that found for GLY in GLY endings and GABA in GABA endings ( $F i g$. 2C). In a fourth class of endings encountered in the $\mathrm{CN}$, the densities of GLY and GABA immunoreactivities were indistinguishable from glial labeling (Fig. 2D).

\section{Characteristics and General Distribution of GLY, GABA, and GLY/GABA Endings in the $\mathrm{CN}$}

Regardless of location in the CN, glycine, GABA, and GLY/GABA endings shared two major morphological features. All three types contained pleomorphic vesicles and were always characterized by symmetric synaptic densities (Figs. 3, 4, 5, 6). In fact, all endings with pleomorphic vesicles and symmetric synaptic densities evaluated were immunolabeled with at least one of the two antibodies. Besides electron-lucent, pleomorphic synaptic vesicles, it was not uncommon to find scattered dense-core vesicles in the three classes of putative inhibitory endings, particularly in AVCN, and overall, in GABA endings (Fig. 1). On the other hand, the vast majority of unlabeled endings contained larger, homogeneously round synaptic vesicles, and asymmetric synaptic densities (Figs. 1, 5, 9).

Some relevant observations regarding the size of the three types of endings deserve mention. First, the smallest endings were consistently of the GABA type. These endings averaged $0.7 \mu \mathrm{m}$ in diameter, and rarely exceeded $1.5 \mu \mathrm{m}$. Second, GLY and GLY/GABA endings had an average size of 1.5 and $1.6 \mu \mathrm{m}$ respectively. However, considerable variations in size were observed especially among GLY/ GABA endings. Endings of this class as large as $4.5 \mu \mathrm{m}$ were found in the DCN, and in general it appeared that larger-sized, labeled endings were more common in the DCN (Figs. 7,8 ).

Differences were noted in the relative occurrences of GLY/GABA, GLY, and GABA terminals. GABA endings were the least common type both in VCN and DCN, and GLY endings appeared to be more abundant than GLY/ GABA endings in VCN, particularly in the caudal part of the posteroventral CN (PVCN). However, in DCN the GLY/GABA ending was the type most frequently observed.

Patterns of distribution of GLY, GABA, and GLY/GABA endings were assessed on the perikarya and proximal dendrites of four major types of $\mathrm{CN}$ projection neurons, including spherical bushy and stellate multipolar cells in the anteroventral CN (AVCN), octopus cells in PVCN, and fusiform cells in DCN. These cell types were identified using ultrastructural criteria established by several previous studies (spherical bushy cells: Schwartz and Gulley, 1978; Oberdorfer et al., 1988; Wenthold et al., 1988; stellate multipolar cells: Cant 1981; Smith and Rhode, 1989; Saint Marie et al., 1993; octopus cells: Kane, 1973, 1977; Moore, 1986, Wenthold et al., 1988; Kolston et al., 1992; fusiform cells: Kane, 1974; Smith and Rhode, 1985). Perhaps the most striking patterns were those encountered on the somata of spherical bushy cells in the rostral AVCN, on which immunolabeled endings were typically organized in distinct clusters (Figs. 3, 10). These clusters contained from two to six immunolabeled endings, and were interposed between the larger, unlabeled terminals of the auditory nerve (Fig. 10). A distinct envelope of astrocytic processes wrapped each cluster (Fig. 3). GLY endings clearly predominated, although they always coexisted with GLY/GABA and GABA endings (Fig. 10). On the primary dendrites, however, immunolabeled terminals were frequently packed together, although they did not form distinct clusters. This was also the case in the neuropil surrounding spherical bushy cell bodies.

The pattern of organization of GLY, GLY/GABA, and GABA endings on spherical bushy cell bodies was in sharp contrast to that typically observed on type I stellate multipolar cells where, sometimes only one or two small GLY or GABA endings, contacted each somal profile (Fig. 10). Axo-somatic GLY/GABA endings were uncommon. However, the primary dendritic trunks of the stellate multipolar cells were apposed by an abundance of GLY, GLY/GABA, and GABA endings. These endings were not arranged in clusters. The perikarya of octopus cells were contacted by an abundance of GLY and unlabeled endings (Figs. 6, 10) and a few GABA endings (Fig. 10). However, GLY/GABA endings were uncommon, and the cluster-like organization of the inhibitory-type terminals was not as obvious as in the spherical bushy cells.

On the perikarya of fusiform cells, the GABA and GLY/ GABA endings were most frequently observed and were distributed in irregular groups around each somal profile, with long stretches of somatic membrane receiving no synaptic contact (Figs. 7, 10). GLY/GABA endings predominated on the trunks of basal and apical dendrites (Fig. 8). In the neuropil of the fusiform cell layer, most of the axodendritic synaptic terminals corresponded to roughly equal proportions of GLY and GLY/GABA endings, particularly in its deeper portions, and were usually found in close proximity to the less numerous, large unlabeled endings of the auditory nerve. The three classes of putative inhibitory endings also contacted the shafts of spiny dendrites in the molecular layer presumably associated with the dendritic arbors of fusiform or cartwheel cells (Fig. 9). Most spinés received unlabeled synaptic boutons containing round vesicles (Fig. 9). However, no clear trend could be established for the predominance of a single class of immunolabeled ending on these dendrites. 

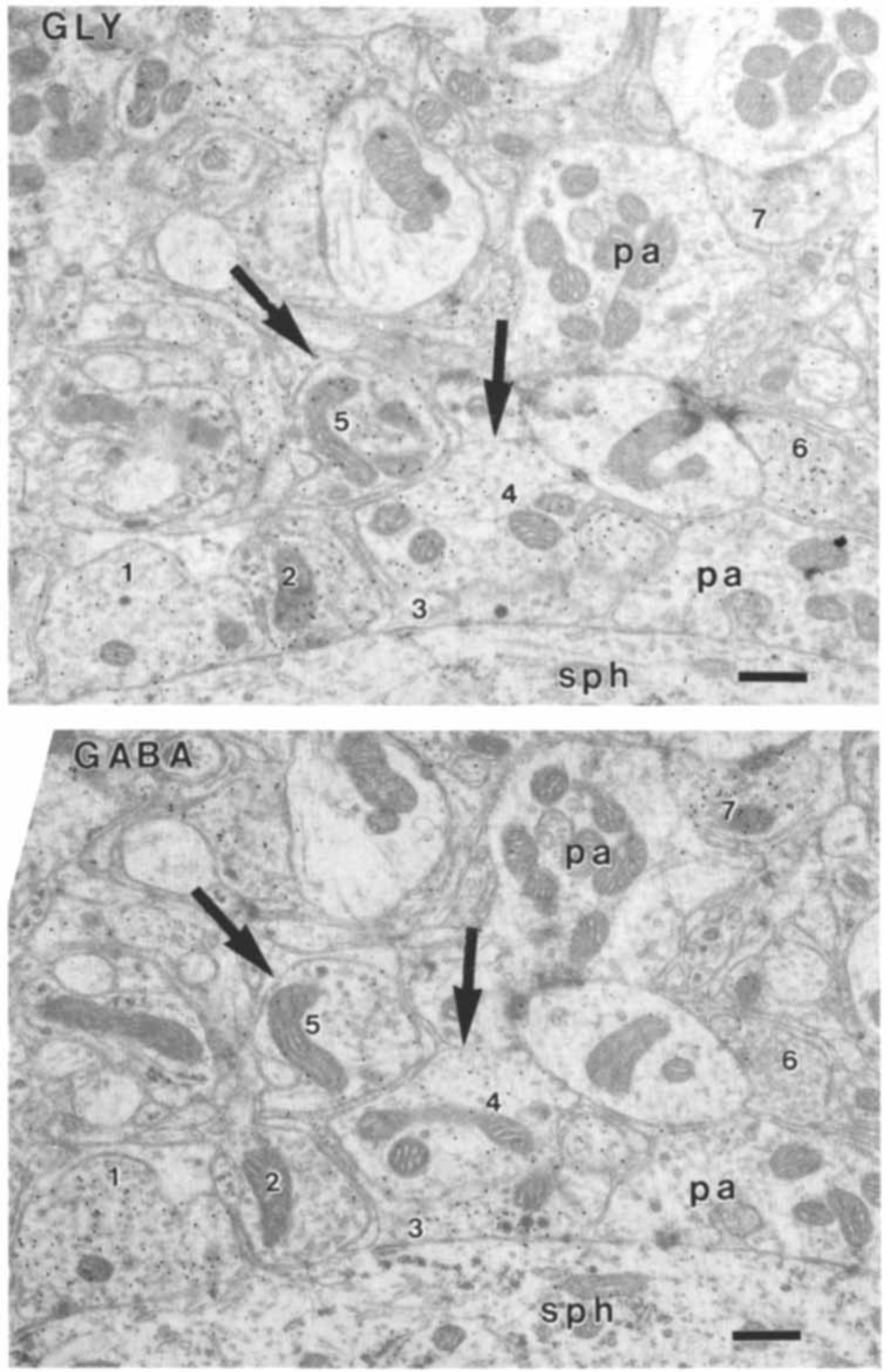

Fig. 1. Glycine (GLY) and $\gamma$-amino butyric acid (GABA) immunoretivities in synaptic terminals of the anteroventral cochlear nucleus VCN). This picture illustrates three types of immunoreactive termiIs found on serial ultrathin sections of the AVCN incubated with LY (top) or GABA (bottom) antibodies, by using an immunogold label. ree immunolabeled terminals $(1,2,3)$ contact the somata of a herical/bushy cell (sph). One (1) contains both GLY and GABA Imunoreactivities. Adjacent to this, a second terminal (2) is immuno- reactive only for GLY. A third one, small and with several dense-core vesicles (3) immunolabels only for GABA. A primary afferent terminal (pa) shows only background levels of GLY immunoreactivity. Similar types of immunoreactive terminals are found in the neuropil $(4,5,6,7)$ : GLY/GABA (4, 5, arrows), GLY (6), or GABA (7). A large unlabeled terminal (pa) containing large round vesicles makes an axo-dendritic contact. Scale bar $=500 \mathrm{~nm}$. 


\section{Glycine and GABA Immunoreactivities in Synaptic Terminals of the $\mathrm{CN}$}

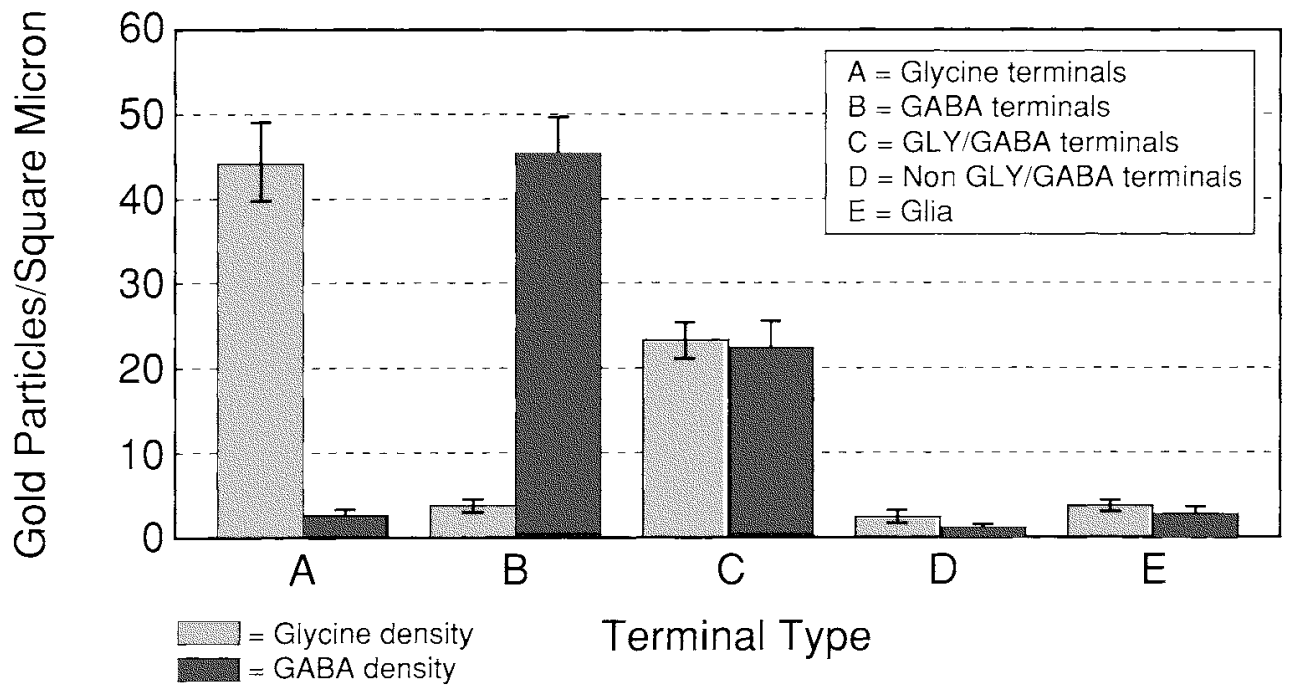

Fig. 2. Mean densities of immunogold labeling (gold particles/ square micron) for GLY and GABA in synaptic endings (Lanes A, B, C, D) and glia (Lane E) in the CN. Differences in GLY immunolabeling in A, GABA immunolabeling in B, and GLY and GABA immunolabeling in

\section{DISCUSSION}

The present study focuses on the synaptic localization and colocalization of the inhibitory amino acids GLY and GABA in the $\mathrm{CN}$ in order to further characterize the inhibitory-type synaptic endings and describe their patterns of distribution on the various types of $\mathrm{CN}$ projection neurons. Colocalization of GABA and GLY has been reported previously in neuronal populations of the CN using light microscopic immunocytochemistry (Wenthold et al., 1987; Oberdofer et al., 1988; Juiz et al., 1989a; Moore and Osen, 1990; Osen et al., 1990, 1991; Kolston et al., 1992). Our findings confirm and expand these observations, demonstrating directly the presence in the CN of synaptic endings containing increased levels of both GLY and GABA immunoreactivities. The major conclusions to be derived from this work are that three populations of inhibitory amino acid immunoreactive endings exist in the $\mathrm{CN}$, each containing either one or both amino acids, and that these terminal classes are differentially distributed on the cell types studied. Taken together, these findings add further support to the extensive evidence indicating a major neurotransmitter role for GLY and GABA in non-primary synapses of the CN (reviewed by Wenthold and Martin, 1984; Caspary, 1986; Wenthold, 1991. See also, Altschuler et al., 1993; Potashner et al., 1993; Saint Marie et al., 1993).

All three classes of terminals revealed by GABA and GLY immunoreactive staining share the morphology classically associated with putative inhibitory synapses (Uchizono, 1965; Pappas and Waxman, 1972), i.e., the presence of pleomorphic vesicles and symmetric pre- and postsynaptic densities. In the $\mathrm{CN}$, these ultrastructural characteristics are common to the majority of non-cochlear nerve (nonprimary) synapses (Lenn and Reese, 1966; Kane, 1977; Schwartz and Gulley, 1978; Cant and Morest, 1979; Tolbert and Morest, 1982; Altschuler et al., 1986a). Further distinction of non-cochlear endings as containing either oval/
$\mathrm{C}$ relative to $\mathrm{D}$ and $\mathrm{E}$ were statistically significant $(P<0.001)$. The lower immunolabeling density for both GABA and GLY in $\mathrm{C}$ relative to levels in A and B also was statistically significant $(P<0.01)$. Vertical bars represent S.E.M. See text for further details. pleomorphic or flattened vesicles (Schwartz and Gulley, 1978; Cant and Morest 1979; Tolbert and Morest, 1982; Smith and Rhode, 1985; Altschuler et al., 1986a; Wenthold et al., 1988) could not be made in our material, probably because of differences in fixation conditions (Valdivia, 1971). However, the generic classification of 'pleomorphic vesicles' (Wouterlood and Mugnaini, 1984; Mugnaini, 1985; Adams and Mugnaini, 1987) assigned to the three classes of immunolabeled endings sufficed to distinguish them from endings with uniformly round, synaptic vesicles and more asymmetric synaptic contacts. These synaptic endings, many of which represent primary input from the auditory nerve (Lenn and Rees, 1966; Kane, 1977; Schwartz and Gulley, 1978; Cant and Morest 1979; Tolbert and Morest, 1982) were never labeled above background for GLY or GABA.

Unlabeled endings with the ultrastructural characteristics described above were not observed, suggesting that all inhibitory synapses in the CN probably utilize GLY and/or GABA as neurotransmitters. Indeed, that virtually all putative inhibitory endings can be classified as GLY, GABA, or GLY/GABA is a significant departure from previous studies on the localization of inhibitory amino acids in $\mathrm{CN}$ synaptic endings, most of which have dealt with the distribution of GAD or GABA immunoreactive endings (Mugnaini, 1985; Shiraishi et al., 1985; Adams and Mugnaini, 1987; Oberdorfer et al. 1988; Saint Marie et al., 1989). In the above studies, substantial numbers of unlabeled noncochlear endings, most probably corresponding to the GLY endings described in this study, were found along with those immunolabeled for GAD or GABA. Therefore, it may be possible to assign GLY and/or GABA to virtually all anatomically-defined 'inhibitory' endings in the CN. This does not preclude, however, the presence of additional neuroactive substances in these synaptic endings. In fact, dense core vesicles typically associated with neuropeptides 

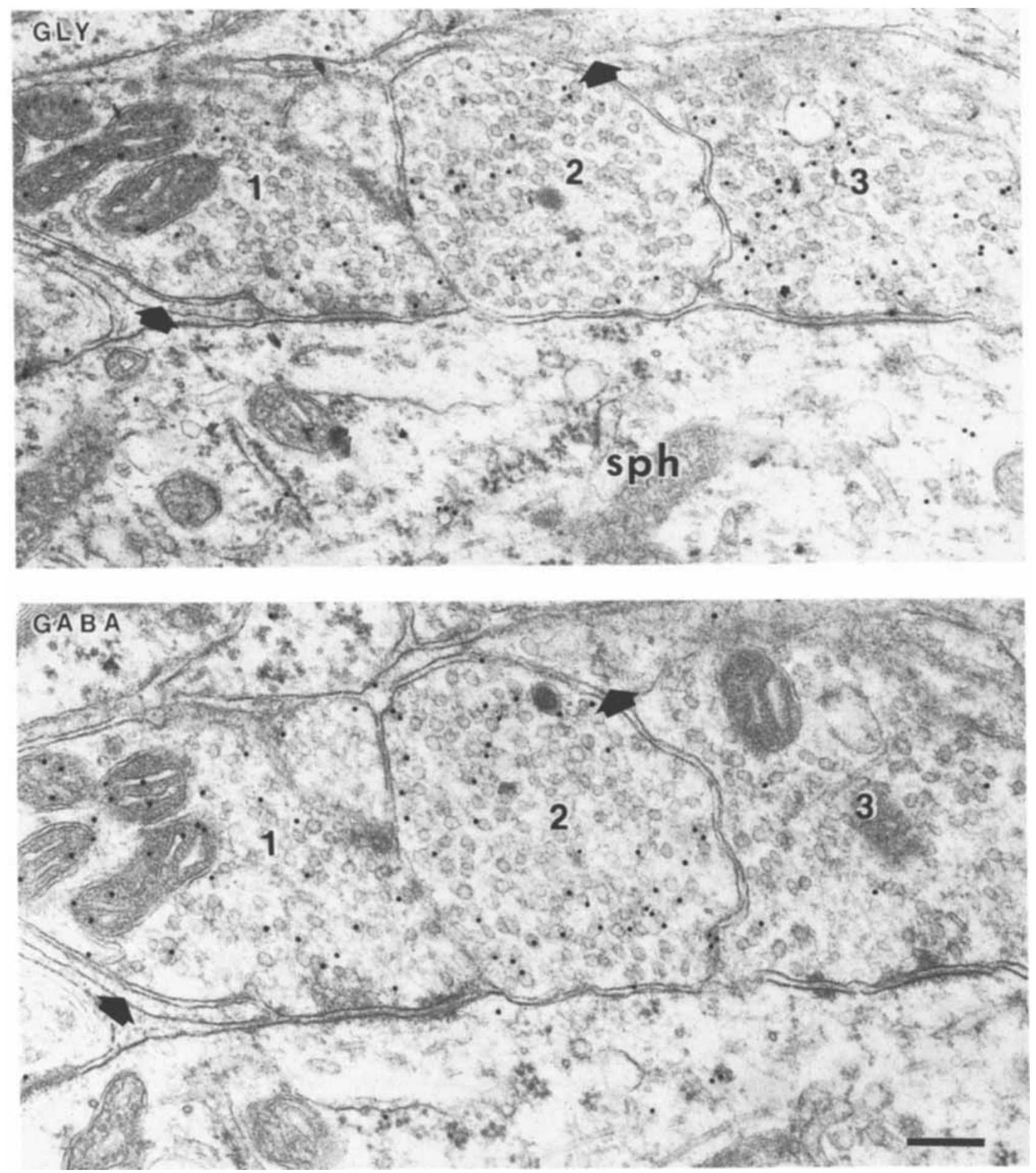

Fig. 3. Three immunoreactive terminals contacting a spherical cell body (sph) in the rostral AVCN. Two of them $(1,2)$ contain both GLY and GABA immunoreactivities. The third is immunolabeled only for GLY (3). Note that the three terminals are closely packed. They are part of a cluster of synaptic endings, whose glial wrapping is indicated by arrowheads. Scale bar $=250 \mathrm{~nm}$.

or catecholamines (Cooper et al., 1985) were observed in many of the immunoreactive terminals, particularly GABA immunopositive endings in the AVCN. Colocalization of IABA and neuropeptides has been described in periolivary and deep DCN neurons that probably project to the VCN (Adams, 1993). Also, Vetter et al. (1993) have reported choline acetyltransferase immunoreactivity in some endings with pleomorphic vesicles and symmetric densities in 


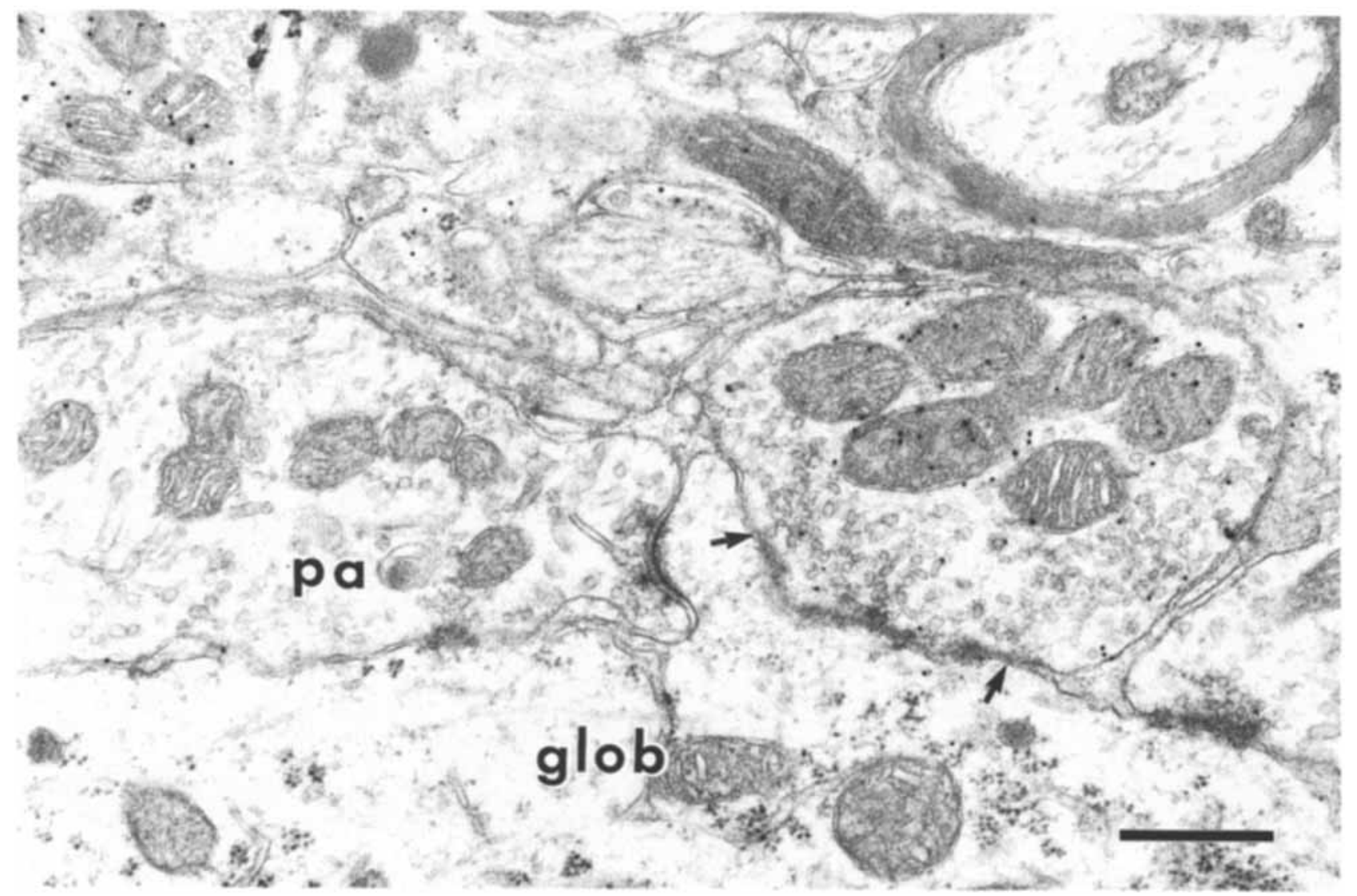

Fig. 4. GLY immunoreactive ending on the somata of a globular bushy cell (glob) the in caudal AVCN. The synaptic area is grazed by the section (arrows), and partially includes a somatic spine. The opposite side of the spine makes contact with an unlabeled primary afferent (pa). Scale bar $=1 \mu \mathrm{m}$.

the CN, thus leaving open the possibility of colocalization of acetylcholine with GABA and/or GLY.

While data from many other studies strongly support synaptic release of GLY and GABA in the $\mathrm{CN}$, they leave unresolved the question of whether both amino acids may be released from the same terminal, as suggested here by the presence of the large population of GLY/GABA endings. There is some evidence from research in other areas of the brain suggesting that both amino acids might represent neurotransmitter pools in GLY/GABA endings. Studies on purified synaptic vesicles from brainstem and spinal cord (Christensen et al., 1990; Burger et al., 1991) indicate the existence of a shared transporter mechanism for the vesicular uptake of GABA and GLY. Ottersen and coworkers (1988) not only observed colocalization of GLY and GABA immunoreactivities in Golgi cell endings in the rat cerebellum, they also suggested that GLY and GABA are coreleased by demonstrating the elimination of both GLY and GABA immunoreactivities from Golgi cell endings, which occurred only in the presence of calcium upon potassiuminduced depolarization of cerebellar slices (Ottersen et al., 1990). In view of its abundance of GLY/GABA endings, it would be interesting to replicate these experiments in the CN.

In the present study, quantitation of the relative numbers of immunolabeled endings was not attempted. However, it was obvious that in general GLY/GABA endings outnumbered GABA endings and matched roughly the abundance of GLY endings. The abundance of GLY/GABA endings may indicate the magnitude of their functional contributions. If it is confirmed that both amino acids are synaptically released from GLY/GABA endings, then the present findings would predict that a substantial amount of GABA available for inhibition in the CN coexists with GLY. As discussed above, however, this coexistence is not restricted to the $\mathrm{CN}$; thus, it may have widespread functional relevance.

The specific inhibitory actions of GLY, GLY/GABA, and GABA endings would be determined in part by the type and localization of their associated receptors. Physiological/ pharmacological studies have shown that GLY and GABAmediated inhibition of $\mathrm{CN}$ neurons is blocked by the antagonist of glycine and GABAA receptors, strychnine and bicuculline respectively (Caspary et al. 1979; Martin et al., 1982; Martin and Dickson, 1983; Martin and Penix, 1983; Caspary, 1986; Caspary et al., 1993; Evans and Zhao; 1993). GLY-dependent, strychnine-sensitive inhibitory postsynaptic potentials have been identified in the CN (Wu and Oertel, 1986; Oertel and Wickesberg, 1993). GLY and GABA receptors have been anatomically localized and mapped in the CN using receptor autoradiographic (Frostholm and Rotter, 1986; Glendenning and Baker, 1988; Juiz et al., 1994) and immunocytochemical methods (Altschuler et al., 1986b; Wenthold et al., 1988; Juiz et al., 1989b). At the synaptic level, immunoreactivity for the $93 \mathrm{Kd}$ GLY receptor-associated anchoring protein (gephyrin) has been 


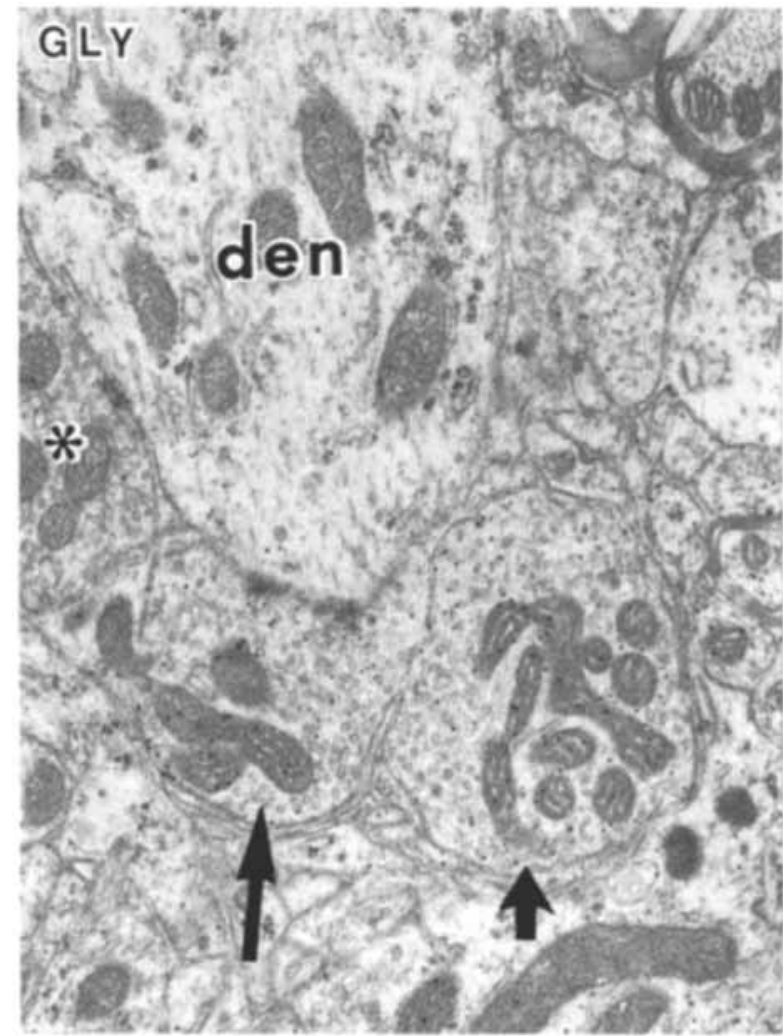

Fig. 5. Dendritic profile (den) in AVCN apposed by several synaptic terminals. One (large arrow) shows co-localization of GLY and GABA immunoreactivities. An adjacent one is immunoreactive only for GLY (small arrow). As in previous examples all these immunolabeled

found postsynaptic to many endings containing pleomorphic or flattened vesicles (Altschuler et al., 1986b; Wenthold et al., 1988; Altschuler et al., 1993). In addition, experiments combining GAD and GLY receptor immunocytochemistry have shown GLY receptor immunoreactivity postsynaptic to GAD immunoreactive endings in the AVCN (Oberdorfer et al., 1987; Altschuler et al., 1993) and spinal cord ('Triller et al., 1987). Although additional confirmatory double labeling studies need to be done, these findings indicate that both GLY and GLY/GABA endings are apposed to GLY receptors.

\section{Relationship to GLY and GABA Receptors in the $\mathrm{CN}$}

The types and distributions of GABA receptors and their association with GABA immunolabeled endings in the $\mathrm{CN}$ is not yet clear. Results from receptor autoradiographic assays for low-affinity GABAA receptors (Frostholm and Rotter, 1986; Glendenning and Baker, 1988; Juiz et al., 1994) and GABAB receptors (Juiz et al., 1994) only partially overlap with the distribution of GABA immunoreactivity in the CN. Similarly, antisera to the $\beta$ subunit of the GABAA receptor labeled the postsynaptic areas beneath many synaptic endings containing pleomorphic vesicles in DCN, but very few in AVCN (Juiz et al., 1989b). The types and distributions of GABA receptors apposing GABA and GLY/GABA terminals in the $\mathrm{CN}$ need to be studied in zreater detail. This is particularly important for receptors issociated with GLY/GABA terminals, because several

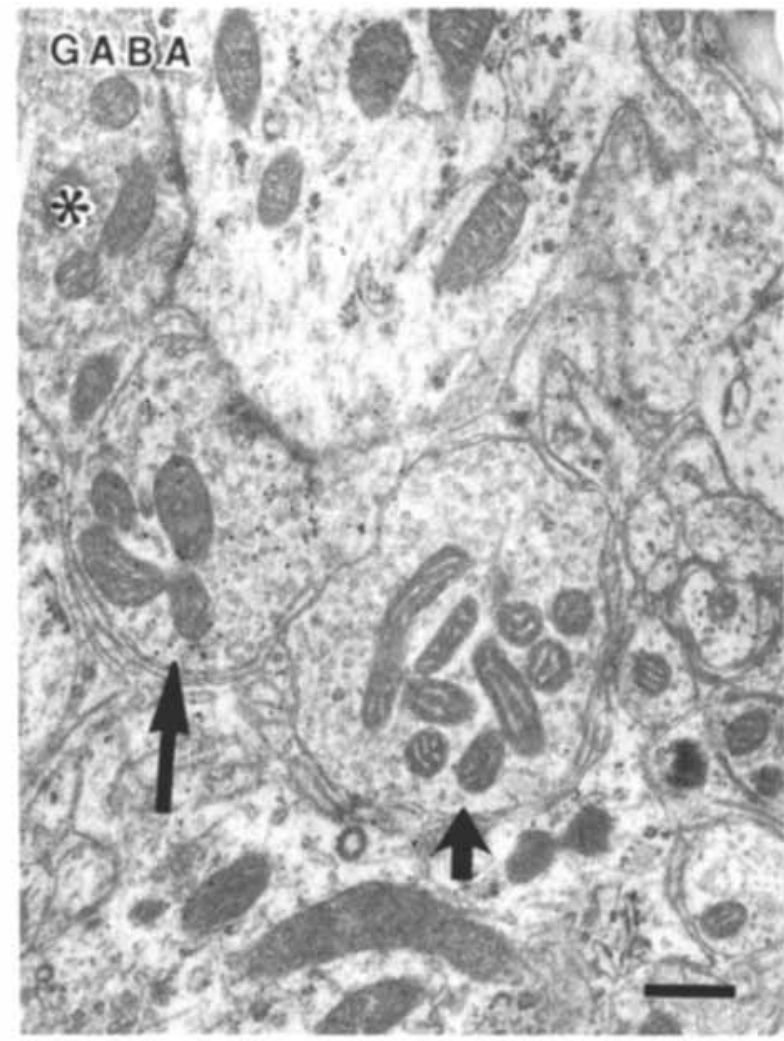

terminals contain pleomorphic vesicles. The asterisk indicates an unlabeled ending with large round vesicles and asymmetric synaptic density, most probably from the auditory nerve. Scale bar $=500 \mathrm{~nm}$.

possibilities exist. Both GLY and GABA could act postsynaptically on their respective receptors (reviewed by 'Triller et al., 1990). The subunits and configuration of the GABA receptor apposing GABA/GLY terminals may be different than that apposing GABA terminals. If this is the case then both antibodies used in immunocytochemical studies and the ligand in receptor binding studies could bind with less affinity. Since GABA/GLY terminals make up the majority of the GABA containing terminals in VCN, it could explain the low binding and immunocytochemical staining in VCN. GABA might also act presynaptically to suppress transmitter release. Finally, the possibility exists for allosteric modulations of GLY receptors by GABA (Werman, 1980; Faber and Korn, 1991).

\section{Patterns of GLY and GABA Input on Major Cell Types in the $\mathrm{CN}$}

Although a detailed analysis of the spatial distribution of GLY, GABA, and GLY/GABA endings was beyond the scope of this study, a number of observations were made on the distribution of immunolabeled endings on the cell bodies of four major types of $\mathrm{CN}$ neurons. Cell-specific patterns of synaptic inputs, probably reflecting differences in function, have been described previously in the $\mathrm{CN}$ (Brawer et al., 1974; Kane, 1977; Cant and Morest, 1979; Smith and Rhode, 1985; Adams and Mugnaini 1987; Kolston et al., 1992), and the present results support and extend these observations. 

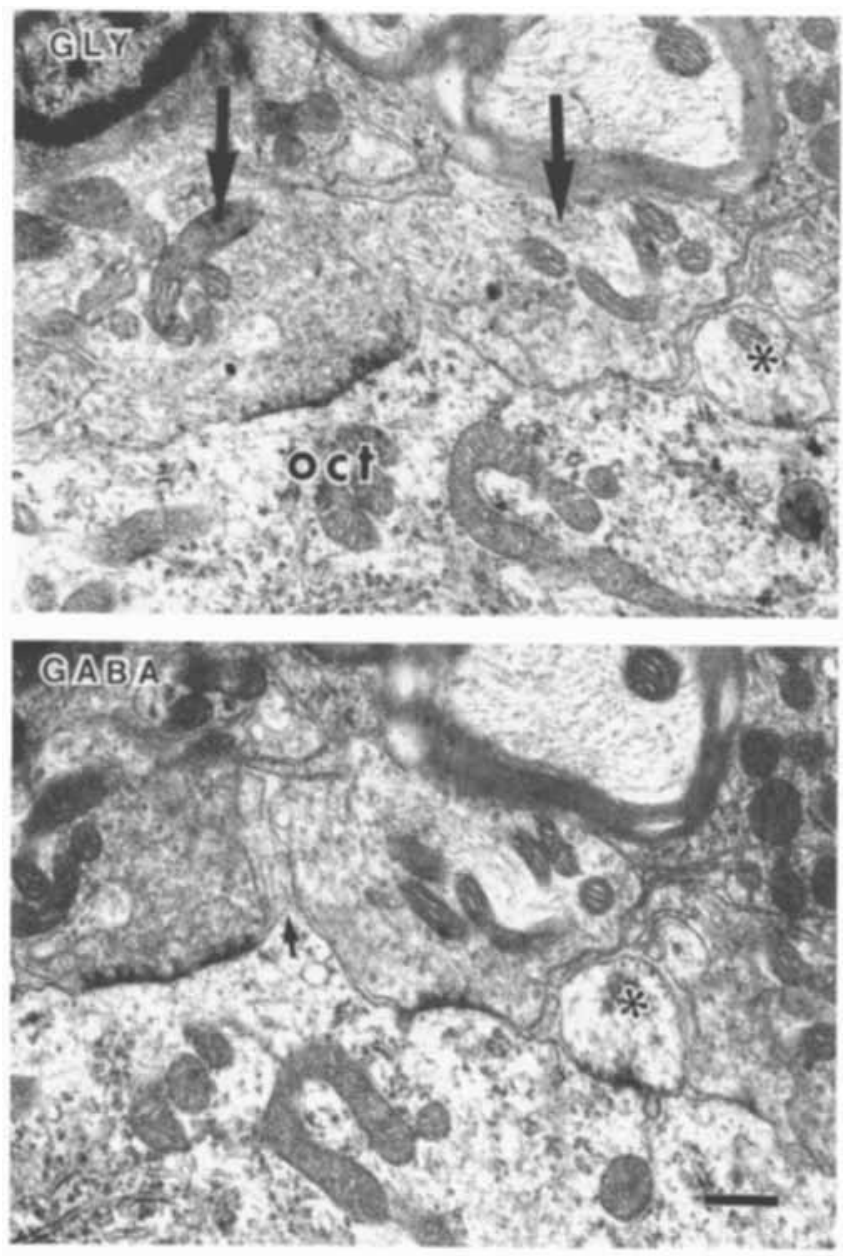

Fig. 6. Serial sections immunostained for GLY and GABA showing two typical endings on the cell body of an octopus cell (oct) which are immunoreactive only for GLY (large arrows in GLY). Notice the small unlabeled terminal (asterisk). Scale bar $=500 \mathrm{~nm}$.

Clusters of non-primary endings have been described on the somata of spherical bushy cells (Cant and Morest, 1979, Saint Marie et al., 1989; Ostapoff and Morest, 1991; Saint Marie et al., 1993), some containing GAD or GABA immunoreactivities (Adams and Mugnaini, 1987; Oberdorfer et al., 1988; Saint Marie et al., 1989, 1993). In our material, the vast majority of the endings in these clusters contained GLY, GABA, or both, with GLY endings prevailing and GABA terminals the least common. In addition, each cluster was covered by an envelope of glial processes. Perhaps by acting as a diffusion barrier, this glial envelope may limit the movement of GLY and GABA away from the underlying synaptic zones, thus enhancing their inhibitory effect. Consistent with these findings, both GABA and GLY appear to produce effective inhibition within the excitatory response area of primary-like and phase-locked units in AVCN, with the GLY effects being slightly more intense than those of GABA (Caspary et al., 1993). The clusters were always situated near unlabeled auditory nerve endings, which were only occasionally embraced by the same glial processes delimiting the "inhibitory cluster." However, although GLY and GLY/GABA endings prevailed on the primary dendrites and, in general, in the neuropil surround- ing spherical/bushy cell bodies, they were not organized in distinct clusters.

Contrary to spherical bushy cells, type I stellate multipolar cells in the AVCN receive sparse axosomatic synaptic input (Cant, 1981; Oberdorfer et al., 1988; Wenthold et al., 1988; Smith and Rhode, 1989; Saint Marie et al., 1993). We found that the few non-cochlear axosomatic terminals immunolabeled either for GLY or GABA, but not both. Indeed, GLY receptor immunoreactivity has been observed apposing axosomatic terminals in stellate multipolar cells (Wenthold et al., 1988). Whenever the primary dendrite of a stellate multipolar cell was identified, it appeared that they were contacted predominantly by GLY endings. However, a complete picture of inhibitory input on stellate multipolar cells cannot be obtained without a thorough description of the distribution of GLY and GABA terminals on their extensive dendritic trees. Intracellular labeling combined with ultrastructural immunocytochemistry will be especially useful to address the spatial organization of putative inhibitory endings on this cell type.

Octopus cell bodies were contacted largely by GLY and, to a lesser extent, by GABA endings. Similar to stellate multipolar cell bodies, GLY/GABA endings were rarely found. The immunolabeled endings did not form distinct clusters, Instead, they tended to be isolated and evenly distributed around the soma. It is generally agreed that GAD immunoreactive endings on octopus cell bodies are sparse and evenly distributed (Adams and Mugnaini, 1987; Saint Marie et al., 1989). Kolston et al. (1992) have described relatively abundant GLY endings on octopus cells in guinea pig, while Wickesberg and Oertel $(1991,1993)$ report less abundant endings on octopus cells in the mouse.

A major characteristic of DCN fusiform cells was the predominance of immunolabeled terminals over unlabeled endings. The abundance of GLY/GABA and GABA endings on the cell body and, in the case of GLY/GABA terminals the primary apical and basal dendritic trunks as well, suggests a fundamental role for these endings in the regulation of excitation at the level of the cell body. On the other hand, the large proportion of GLY and GLY/GABA axodendritic endings in the neuropil of the fusiform cell layer and their proximity to unlabeled endings of the auditory nerve indicate that both types of endings may control the spread of primary afferent excitation along the dendrites. These findings are consistent with light and electron microscopic observations on the morphology and distribution of GLY and/or GABA immunoreactive puncta in the DCN (Kane, 1977; Wouterlood and Mugnaini, 1984; Mugnaini, 1985; Smith and Rhode, 1985; Kolstan et al., 1992).

\section{Potential Origins of the GLY and GABA Inputs}

The precise origins of the different classes of GLY and/or GABA immunoreactive endings described in this study still remain to be fully explored. GLY and/or GABA immunoreactive cell bodies have been described in the VCN (Wenthold et al., 1986, 1987; Kolston et al., 1992). However, they are sparse, suggesting that the majority of GLY, GLY/ GABA, and GABA endings originate outside this division. A major source of putative glycinergic input to the AVCN are GLY immunoreactive tuberculoventral or vertical cells in deep DCN (Cant and Morest, 1978; Lorente de No, 1981; Wickesberg and Oertel, 1988; Oertel and Wu, 1989; Saint Marie et al., 1991, 1993; Osen, 1990; Kolston et al., 1992; 

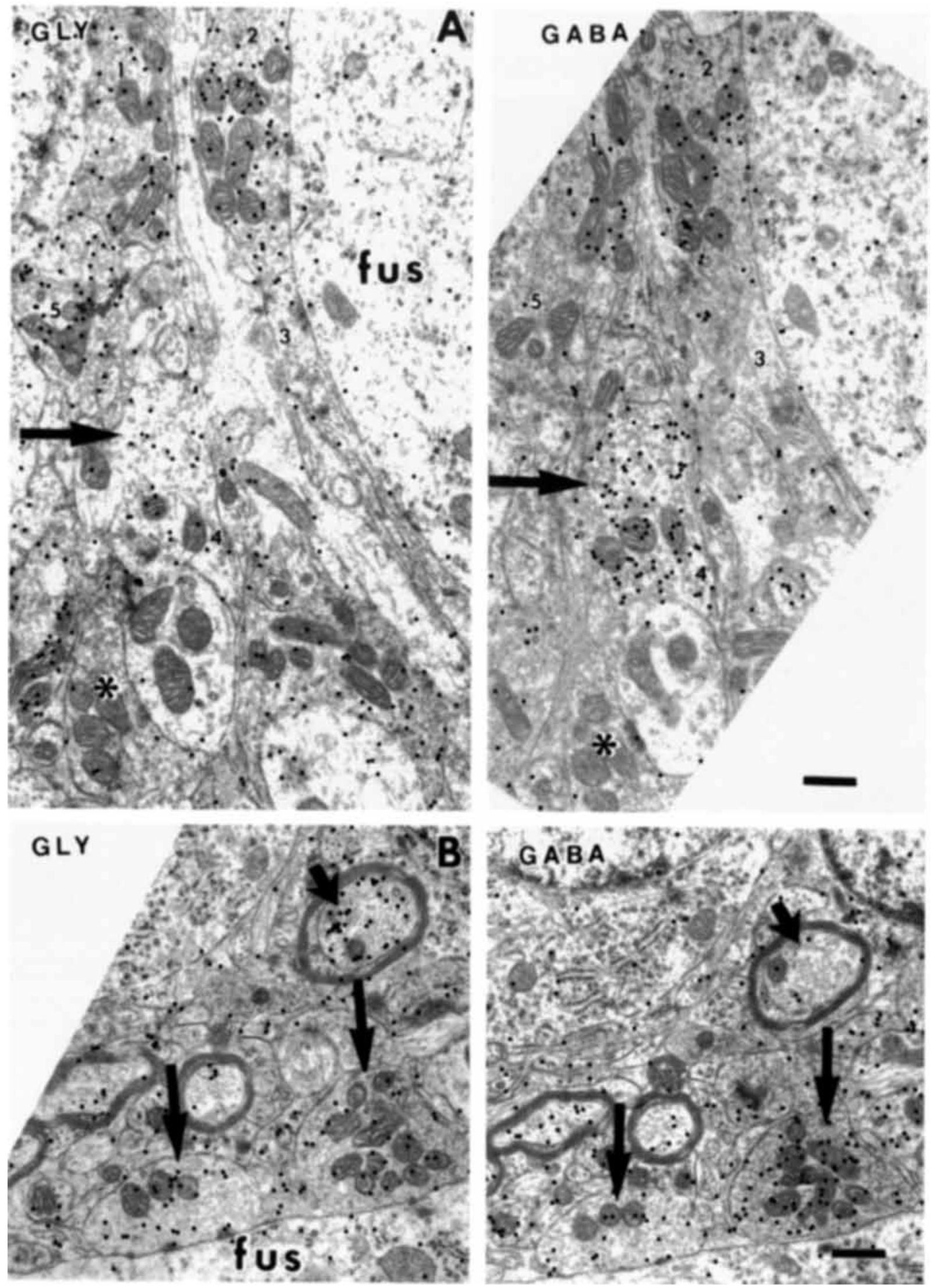

Fig. 7. Visualization of colloidal gold particles was enhanced in this figure. Electron microgaph negatives were digitized on a Leaf Scanner 45 at 1060 pixels/inch resolution. Colloidal gold particles were visualized and thresholded at high magnification and were all replaced with larger dots using the pencil tool of Adobe Photoshop on a Power Macinstosh $8100 / 100 \mathrm{AV}$. The image was then printed on a Kodak XL 8600 PS Printer. A: GLY and GABA immunoreactive terminals on a fusiform cell body (fus) and neuropil of the fusiform cell layer. Terminals 1,2 , and 4 contain both GLY and GABA immunoreactivities.

Terminal 5 is immunoreactive only for GLY. The small ending 3 is not immunolabeled. The asterisk also indicates an unlabeled ending. The elongated ending 2 is the most characteristic type of co-labeled terminal found in the fusiform cell layer. Note also the large size of co-labeled terminal 4 (arrow) compared with the size of dendrite it contacts. $\mathbf{B}$ Two co-labeled terminals (large arrows) on a fusiform cell body (fus). The cross sectioned profile of an axon immunoreactive only for GLY is also shown (small arrow). Scale bars $=550 \mathrm{~nm}$ in A, $500 \mathrm{~nm}$ in B. 


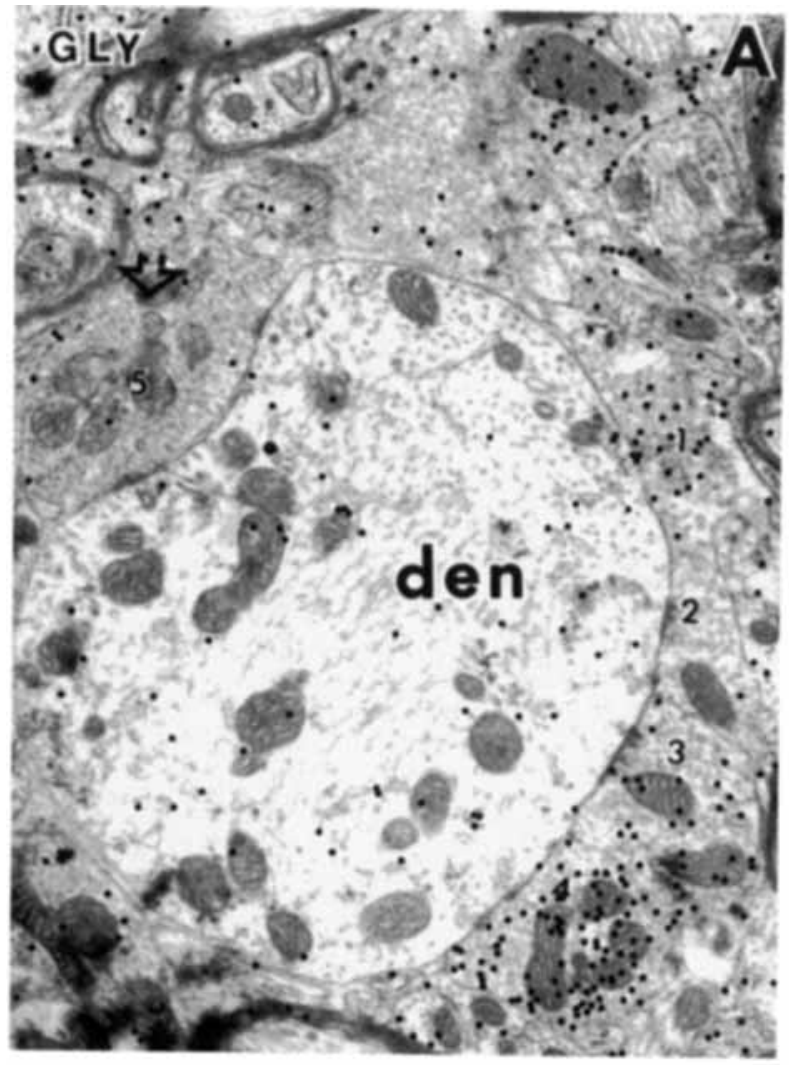

\section{G A B A}
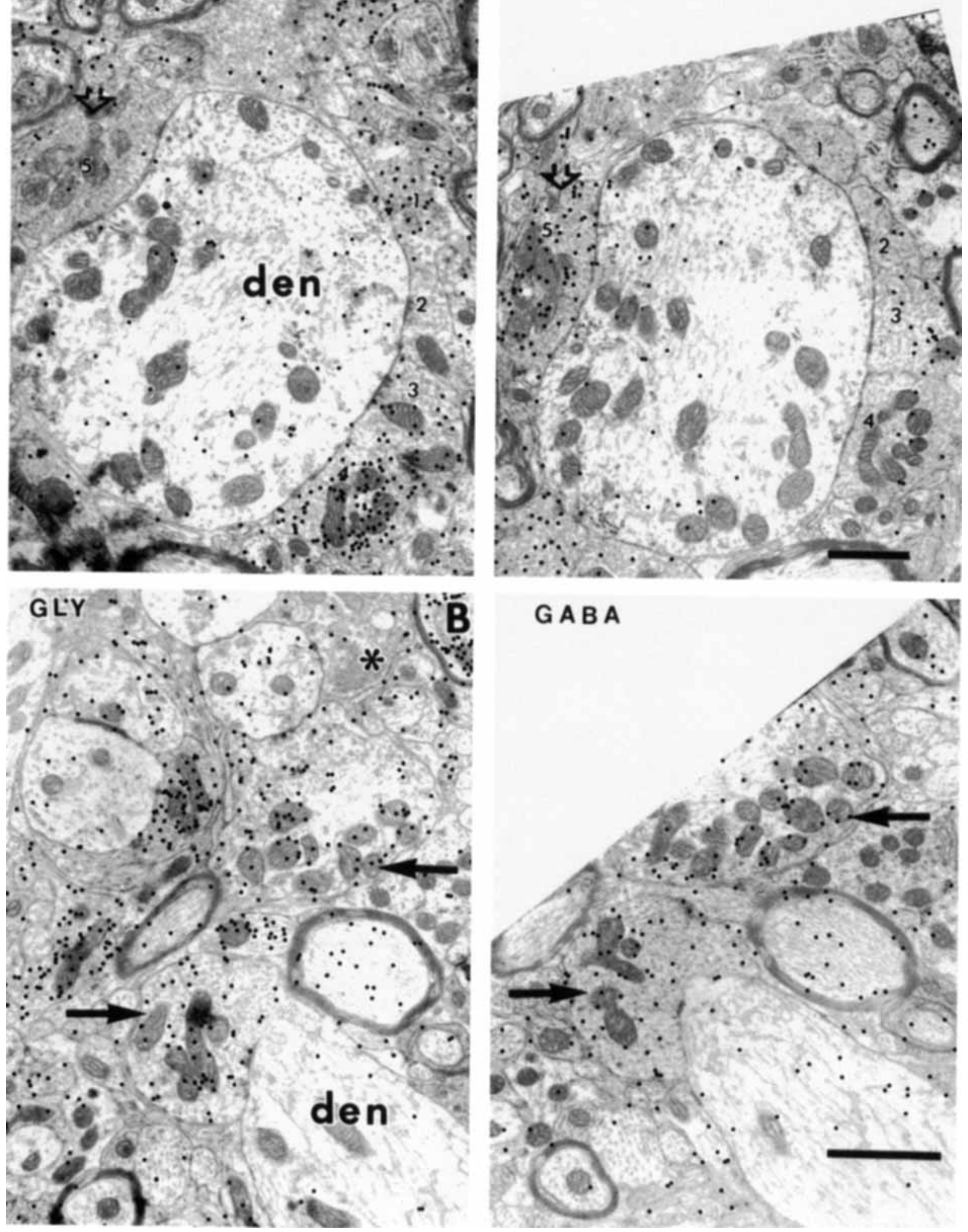

Fig. 8. Visualization of colloidal gold particles was enhanced in this figure. Electron microgaph negatives were digitized on a Leaf Scanner 45 at 1060 pixels/inch resolution. Colloidal gold particles were visualized and thresholded at high magnification and were all replaced with larger dots using the pencil tool of Adobe Photoshop on a Power Macinstosh 8100/100 AV. The image was then printed on a Kodak XL 8600 PS Printer. A: Thick dendrite in the deep fusiform cell layer, probably belonging to a fusiform cell. Several immunoreactive endings contact the unlabeled dendritic profile. 1 is GLY immunoreactive, 2 is unlabeled, 3 and 4 contain both GLY and GABA immunoreactivities,

and 5 is immunreactive only for GABA. Terminals such as 5 (open arrow) are the among the largest GABA terminals found throughout the cochlear nucleus. B: Neuropil of the upper fusiform layer. Two endings co-labeled for GABA and GLY are shown (arrows). One of them contacts the apical dendrite of a fusiform cell (den), which shows only background levels of immunogold labeling. 'This is the most abundant and characteristic type of immunolabeled terminal found on these dendrites. The second terminal is large, with a filamentous core and contacts a small caliber dendrite. Note the unlabeled terminal with large round vesicles (asterisk). Scale bars $=1 \mu \mathrm{m}$ in A, $2 \mu \mathrm{m}$ in B. 

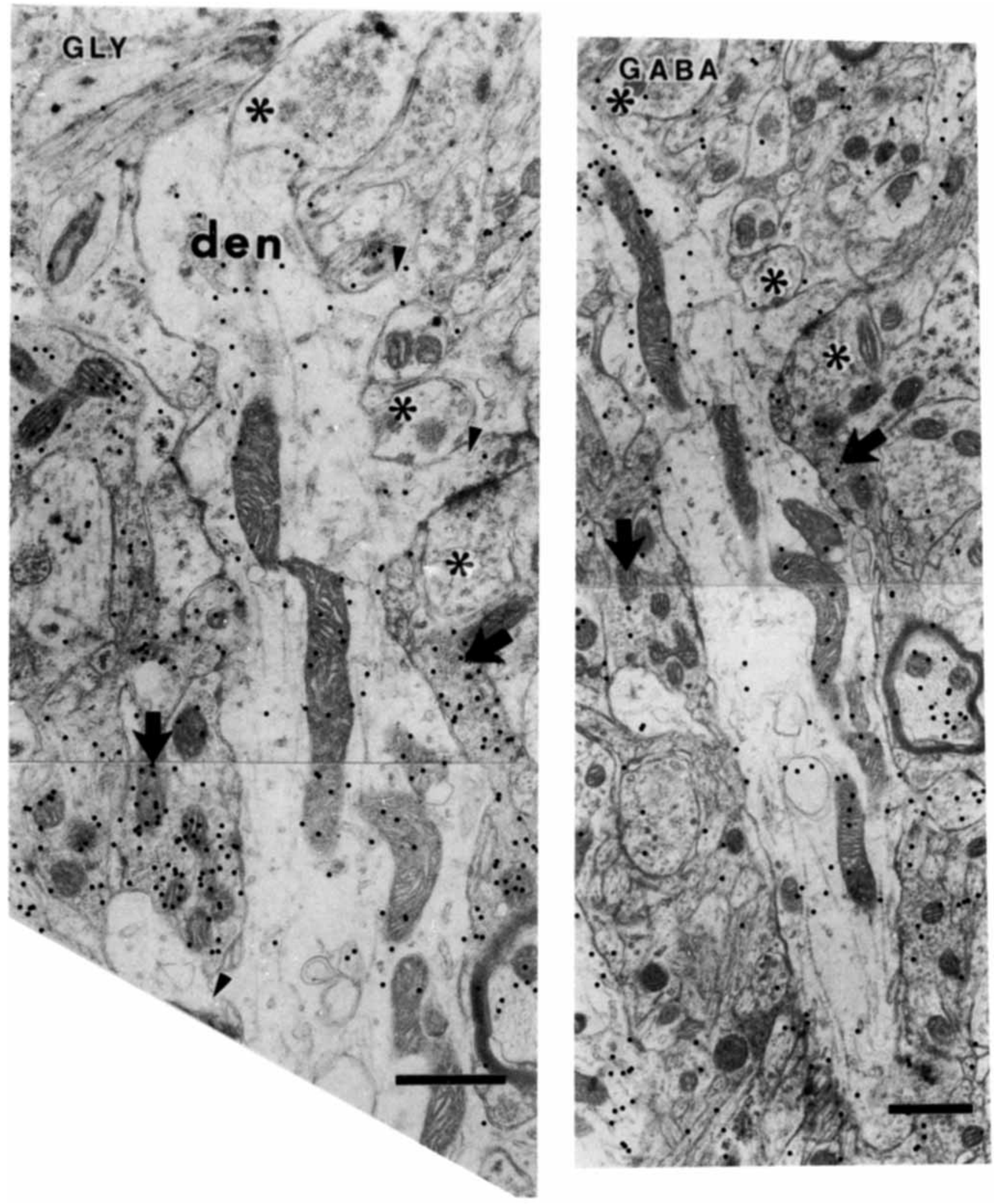

Fig. 9. Montages from the molecular layer of the DCN showing a distal dendrite (den) of a cartwheel neuron, in which the visualization of colloidal gold particles was enhanced. A negative of the montage was digitized on a Leaf Scanner 45 at 1060 pixels/inch resolution. Colloidal gold particles were visualized and thresholded at high magnification. and were all replaced with larger dots using the pencil tool of Adobe Photoshop on a Power Macinstosh $8100 / 100 \mathrm{AV}$. The enhanced image was then printed on a Kodak XL 8600 PS Printer. Note the prominent spines (arrowheads). Magnification is different in GLY and GABA. The dendrite contains GLY and GABA immunoreactivities. The asterisks indicate the most abundant terminal type found on these dendrites. These endings contact mainly spines but also dendritic shafts, contain large round vesicles and never immunolabel over background levels. Immunolabeled terminals generally contact dendritic shafts. In this example, two GLY immunoreactive endings are shown (arrows). Scale bars $=2 \mu \mathrm{m}$ for GLY, $1 \mu \mathrm{m}$ for GABA. 

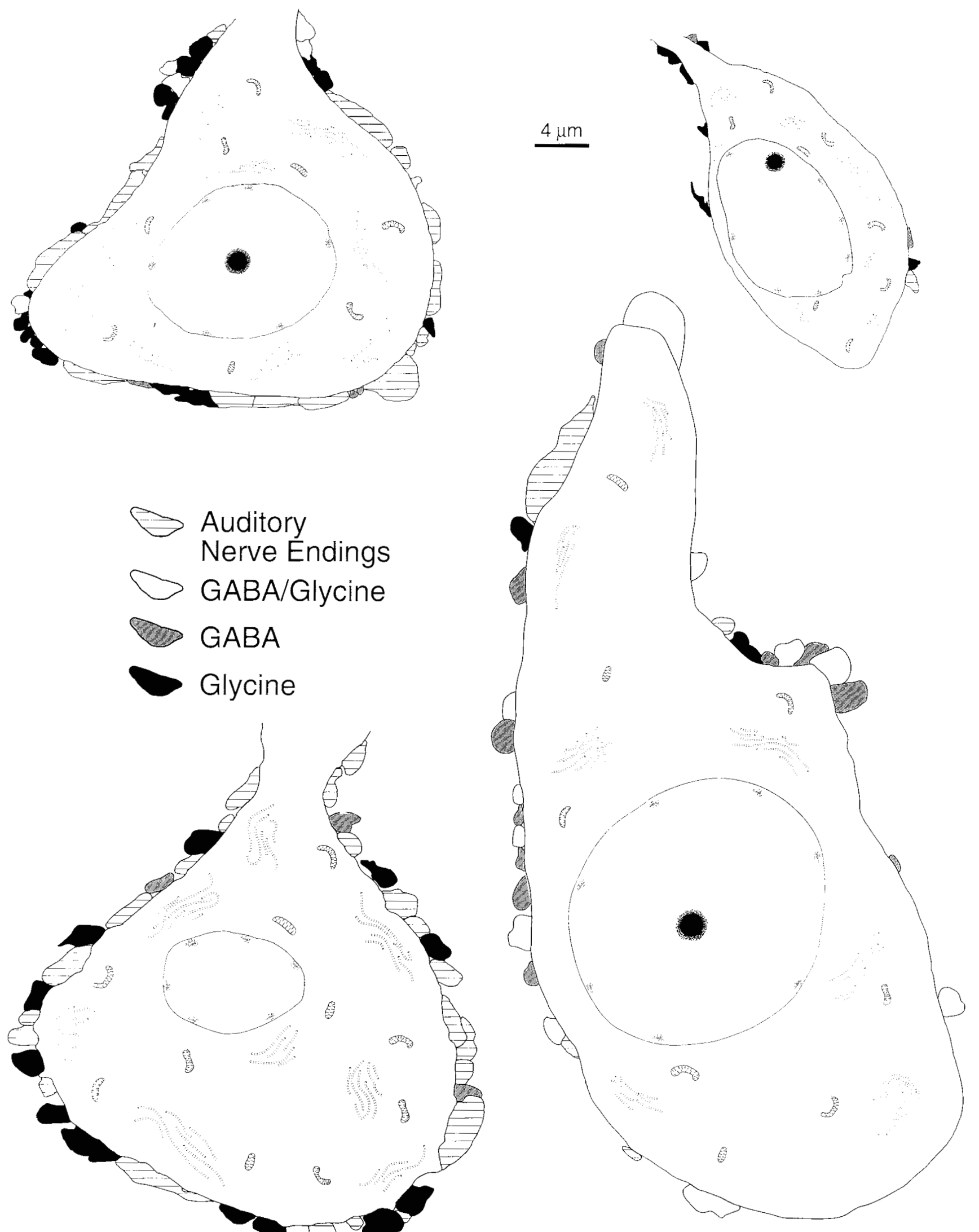

Fig. 10. Composite drawings based on serial ultrathin sections of the cochlear nucleus immunostained for GLY and GABA. Four major cell types and the terminals apposing them are shown. Note the differences in the number, types, and distribution of the different

terminal types among a spherical bushy cells (upper left), a type I stellate multipolar in the AVCN (upper right), an octopus cell in the PVCN (lower left), and a fusiform cell in the dorsal cochlear nucleus (DCN) (lower right). See text for further details. 
Oertel and Wickesberg, 1993). These neurons may be a source of many GLY endings in AVCN, but not the only one. Only $50 \%$ of the GABA and GLY terminals on a typical globular bushy cell were found to originate in DCN (Altschuler et al., 1993). Neurons projecting to the AVCN from the lateral and ventral nucleus of the trapezoid body as well as other periolivary cell groups are GLY and/or GABA immunoreactive (Mugnaini and Oertel, 1985; Adams and Mugnaini, 1987; Ostapoff and Morest., 1991; Helfert et al., 1989; Saint Marie et al., 1993) or accumulate [3H]GLY or [3H]GABA upon injection in the CN (Potashner et al., 1985; Staatz-Benson and Potashner, 1987, 1988; Benson and Potashner, 1990, Ostapoff et al., 1990; Potashner et al., 1993). It has been reported that approximately one-third of periolivary cell bodies immunoreactive for GLY and GABA and projecting to the CN, stain for both GLY and GABA (Saint Marie et al., 1993). Therefore, periolivary cell groups, especially neurons in LNTB and VNTB, could be major sources of GLY/GABA, GLY, and GABA endings in AVCN. The same sources may be the origin of immunolabeled endings in PVCN. However, in the octopus cell area of this division, GLY endings probably do not originate from vertical cells in DCN (Wickesberg and Oertel, 1991, 1993). A pathway connecting the right and left cochlear nuclei has been reported to be glycinergic (Wenthold, 1987; Saint Marie et al., 1993). Less is known about inhibitory projections from other auditory nuclei to the VCN (reviewed by Spangler and Warr, 1991), although the inferior colliculus does not seem to be involved in inhibitory projections to the CN (Ostapoff et al., 1990; Saint Marie et al., 1993). Studies combining anterograde tract-tracing with ultrastructural immunocytochemistry will be necessary to unravel additional sources of GLY, GLY/GABA, and GABA endings in the VCN.

Contrary to VCN, many immunolabeled endings in the superficial DCN originate from local circuit interneurons. Cartwheel cells (Brawer et al., 1974; Wouterlood and Mugnaini, 1984; Mugnaini, 1985; Moore, 1986) are neurons preferentially located in the superficial portions of the fusiform cell layer, whose axons arborize and terminate in the superficial DCN (Oertel and Wu, 1989). Cartwheel cell somata stain for both GABA and GLY (Mugnaini, 1985; Wenthold et al., 1986; Oberdorfer et al., 1987; Wenthold et al., 1987; Kolston et al., 1992). Synaptic endings of cartwheel cells labeled with an antibody against a cell-specific peptide (Berrebi and Mugnaini, 1991) have patterns of distribution very similar to our GLY/GABA endings. It is therefore very likely that a large proportion of GLY/GABA endings in DCN originate from cartwheel cells. Another source of GLY/GABA endings may be Golgi cells (Mugnaini et al., 1980), which were recently shown to stain for both GABA and GLY (Kolston et al., 1992). As mentioned above, most vertical cell bodies in deep DCN label exclusively for GLY (Saint Marie et al., 1991; Kolston et al., 1992). Axon collaterals of these neurons arborize extensively in the fusiform cell layer ( $\mathrm{Wu}$ and Oertel, 1986). Therefore, at least part of the GLY endings in DCN seemingly arise from vertical cells. Less information is available about the possible origins of GABA endings, although some may arise in the molecular layer from stellate cells that immunostain for GAD or GABA (Wouterlood et al, 1984; Mugnaini, 1985; Kolston et al., 1992). However, despite evidence indicating a large proportion of GLY, GLY/GABA, and GABA endings originating from intrinsic neurons, the contribution of extrinsic sources to inhibitory terminals in the DCN is probably substantial as well and needs to be studied in detail. There are important projections to the DCN from periolivary nuclei, nuclei of the lateral lemniscus, and inferior colliculi (reviewed by Spangler and Warr, 1991) and there is evidence, at least for periolivary cell groups, that some of these descending projections may use GLY and/or GABA as transmitters (Benson and Potashner, 1990; Ostapoff et al., 1990; Potashner et al., 1993; Saint Marie et al., 1993).

\section{ACKNOWLEDGMENT}

This work was supported by NIDCD grant DC00383.

\section{LITERATURE CITED}

Adams, J.C. (1993) Non-primary inputs to the cochlear nucleus visualized using immunocytochemistry. In M. Merchan, J. Juiz, D. Godfrey, and E. Mugnaini (eds): The Mammalian Cochlear Nuclei: Organization and Function. New York: Plenum Press, pp. 133-142.

Adams, J.C., and E. Mugnaini (1987) Patterns of glutamate decarboxylase immunostaining in the feline cochlear nuclear complex studied with silver enhancement and electron microscopy. J. Comp. Neurol. 262: $375-401$.

Altschuler, R.A., D.W. Hoffman, and R.J. Wenthold (1986a) Neurotransmitters of the cochlea and cochlear nucleus: Immunocytochemical evidence. Am. J. Otolaryngol. 7:100-106.

Altschuler, R.A., H. Betz, M.H. Parakkal, K.A. Reeks, and R.J. Wenthold (1986b) Identification of glycinergic synapses in the cochlear nucleus through immunocytochemical localization of the postsynaptic receptor. Brain Res. 369:316-320.

Altschuler, R.A., J.M. Juiz, S.E. Shore, S.C. Bledsoe, R.H. Helfert, and R.J. Wenthold (1993) Inhibitory amino acid synapses and pathways in the ventral cochlear nucleus. In M. Merchan, J. Juiz, D. Godfrey, and E. Mugnaini (eds): The Mammalian Cochlear Nuclei: Organization and Function. New York: Plenum Press, pp. 211-224.

Aoki, E., R. Semba, H. Keino, K. Kato, and S. Kashiwamata (1988) GLY-like immunoreactivity in the rat auditory pathway. Brain Res. 442:63-71.

Benson, C., and S.J. Potashner (1990) Retrograde transport of 3 H GLY from the cochlear nucleus to the superior olive in the guinea pig. J. Comp. Neurol. 296:1-12.

Berrebi, A.S., and E. Mugnaini (1991) Distribution and targets of the cartwheel cell axon in the guinea pig dorsal cochlear nucleus. Anat. Embryol. 183:427 -454

Brawer, J.R., D.K. Morest, and E.C. Kane (1974) The neuronal architecture of the cochlear nucleus of the cat. J. Comp. Neurol. 155:251-300.

Burger, P.M., J. HelI, E. Mehl, C. Krasel, F. Lottspeich, and R. Jahn (1991) GABA and glycine in synaptic vesicles: Storage and transport characteristics. Neuron 7:287-293.

Cant, N.B. (1981) The fine structure of two types of stellate cells in the anterior division of the anteroventral cochlear nucleus of the cat. Neuroseience 6:2643-2655.

Cant, N.B., and D.K. Morest (1979) The bushy cells in the anteroventral cochlear nucleus of the eat study with the electron microscope. Neuroscience 4:1925-1945.

Carr C.E., I. Fujita, and M. Konishi (1989) Distribution of GABAergic neurons and terminals in the auditory system of the barn owl. J. Comp. Neurol. 286:190-207

Caspary, D.M. (1986) Cochlear nuclei: Functional neuropharmacology of the principal cell types. In R.A. Altschuler, D.W. Hoffmann, and R.P. Bobbin (eds): Neurobiology of Hearing: The Cochlea. New York: Raven Press, pp. 303-332.

Caspary, D.M., D.C. Havey, and C.L. Faingold (1979) Effects of microiontophoretically applied GLY and GABA on neuronal response patterns in the cochlear nuclei. Brain Res. 172:179-185.

Caspary, D.M., L.P. Rybak, and C.M. Faingold (1985) The effects of excitatory and inhibitory amino acid neurotransmitters on the response properties of brainstem auditory neurons. In D.G. Dreseher (ed): Auditory Biochemistry. Springfield, IL: Charles C. Thomas, pp. 198-226.

Caspary, D.M., P.S. Palombi, P.M. Backoff, R.H. Helfert, and P.G. Finlayson (1993) GABA and glycine inputs control discharge rate within the excitatory response area of primary-like and phase-locked AVCN neurons. In M. Merchan, J. Juiz, D. Godfrey, and E. Mugnaini (eds): The 
Mammalian Cochlear Nuclei: Organization and Function. New York: Plenum Press, pp. 239-252.

Christensen, H., E.M. Fyske, and F. Fonnum (1990) Uptake of glycine int synaptic vesicles isolated from the rat spinal cord. J. Neurochem. $54: 1142-1147$.

Code R.A., and E.W. Rubel (1989) Glycine-immunoreactivity in the auditory brain stem of the chick. Hear. Res. 40:167-172.

Cooper, J.C., F.E. Bloom, and R.H. Roth (1985) The Biochemical Basis of Neuropharmacology. New York: Oxford University Press.

Evans, E.F., and W. Zhao (1993) Neuropharmacological and neurophysiological dissection of inhibition in the mammalian dorsal cochlear nucleus. In M. Merchan, J. Juiz, D. Godfrey, and E. Mugnaini (eds): The Mammalian Cochlear Nuclei: Organization and Function. New York: Plenum Press, pp. $253-266$.

Faber. D.S. and H. Korn (1991) Do some M-cell glyicne receptors interact with GABA? Soc. Neurosci. Abst. 17:100.3.

Frostholm A., and A. Rotter (1986) Autoradiographic localization of receptors in the cochlear nucleus of the mouse. Brain Res. Bull. 16:189-203.

Glendenning, K.K., and B.N. Baker (1988) Neuroanatomical distribution of receptors for three potential inhibitory neurotransmitters in the brain stem auditory nuclei of the cat. J. Comp. Neurol. 275:288-308.

Godfrey, D.A., J.A. Parli, J.D. Dunn, and C.D. Ross (1988) Neurotransmitter microchemistry of the cochlear nucleus and the superior olivary complex. In J. Syka, and R.L. Masterton (eds): Auditory Pathways. New York; Plenum Press, pp 107-121.

Helfert, R.H., J.M. Bonneau, R.J. Wenthold, and R.A. Altschuler (1989) GABA and glycine immunoreactivity in the guinea pig superior olivary complex. Brain Res. 501:269-286.

Helfert, R.H., J.M. Juiz, S.C. Bledsoe, J.M. Bonneau, R.J. Wenthold, and R.A. Altschuler (1992) Patterns of glutamate, glycine and GABA immunolabeling in four synaptic terminal classes in the lateral superior olive of the guinea pig. J. Comp. Neurol. 323:305-325.

Juiz, J.M., J.M. Bonneau, R.H. Helfert, R.J. Wenthold, and R.A. Altschuler (1989a) GABA and glycine immunoreactivities in the guinea pig cochlear nucleus: Ultrastructural co-labeling studies. Abstracts of the XIIth Association for Research in Otolaryngology Midwinter Meeting, pp. 12.

Juiz. J.M. R.H. Helfert, R.J. Wenthold, A.L. De Blas, and R.A. Altschuler (1989b) Immunocytochemical localization of the GABAA/benzodiazepine receptor in the guinea pig cochlear nucleus: Evidence for receptor localization heterogeneity. Brain Res. 504:173-179.

Juiz J.M. R.L. Albin, R.H. Helfert, and R.A. Altschuler (1994) Distribution of GABAA and GABAB binding sites in the cochlear nucleus of the guinea pig. Brain Res. 639:193-201

Kane, E.S. (1973) Octopus cells in the cochlear nucleus of the cat: Heterotypic synapses upon homotypic neurons. Int. J. Neurosci. 5:251-279.

Kane, E.S. (1974) Synaptic organization in the dorsal cochlear nucleus of the cat: A light and electron microscopic study. J. Comp. Neurol. 155 $301-330$.

Kane E.S. (1977) Descending inputs to the cat dorsal cochlear nucleus: an electron microscopic study. J. Neurocytol. 6:583-605.

Kolston, J., K.K. Osen, C.M. Hackney, O.P. Ottersen, and J. StormMathissen (1992) An atlas of glycine and GABA-like immunoreactivity and colocalization in the cochlear nuclear complex of the guinea pig. Anat. Fmbryol. 186:443-465.

Lenn. N.J. and T.S. Reese (1966) The fine structure of nerve endings in the nucleus of the trapezoid body and the ventral cochlear nucleus. Am. J Anat. 118:375-389.

Lorente de No, R. (1981) The primary acoustic nuclei. R. Lorente de No (ed) New York: Raven Press, pp. 1-169.

Martin, M.R. and J.W. Dickson (1983) Lateral inhibition in the anteroventrai cochlear nucleus of the cat: A microiontophoretic study. Hear. Res. $9: 35-41$

Martin, M.R., and L.P. Penix (1983) Comparison of the effects of bicuculline and strychnine on brain stem auditory evoked potentials in the cat. Br. J. Pharmacol. 78:75-77.

Martin, M.R., J.W. Dickson, and J. Fex (1982) Bicuculline, strychnine and depressant amino acid responses in the anteroventral cochlear nucleus of the cat. Neuropharmacol. 21(3):201-207.

McGeer, P.I.. J.C. Eccles, and E.G. McGeer (1987) Inhibitory amino acid neurotransmitters. In P.L. McGeer, J.C. Eccles, and E.G. McGeer (eds): Molecular Neurobiology of the Mammalian Brain. New York: Plenum Press, pp. 197-234.

Moore, J.K. 11986) Cochlear nuclei: Relationship to the auditory nerve. In R.A. Altschuler, D.W. Hoffman, and R.P. Bobbin (eds): Neurobiology of Hearing: The Cochlea. New York: Raven Press, pp. 283-301.
Moore, J.K., and R.Y. Moore (1987) Glutamic acid decarboxylase-like immunoreactivity in the brainstem auditory nuclei of the rat. J. Comp. Neurol. 260:157-174.

Moore, J.K., and K.K. Osen (1990) Colocalization of GABA-like and glycine like immunoreactivities in brainstem auditory nuclei of the baboon (Papio Anubis). Soc. Neurosci. Abst. 16:716.

Morest, D.K. (1993) The cellular basis for signal processing in the mammalian cochlear nuclei. In M. Merchan, J. Juiz, D. Godfrey, and E. Mugnaini (eds): 'The Mammalian Cochlear Nuclei: Organization and Function. New York: Plenum Press, pp. 1-18.

Mugnaini, E. (1985) GABA neurons in the superficial layers of the rat dorsal cochlear nucleus: Light and electron microscopic immunocytochemistry. J. Comp. Neurol. 235:61-81.

Mugnaini E., and W.H. Oertel (1985) An atlas of the distribution of GABAergic neurons and terminals in the rat CNS as revealed by GAD immunocytochemistry. In A. Bjorklund, and T. Hokfelt (eds): Handbook of Chemical Neuroanatomy, Vol. 4: GABA and Neuropeptides in the CNS. Part 1. Amsterdam: Elsevier, pp. 436-608.

Mugnaini, E., K.K. Osen, A.L. Dahl, V.L. Friedrich, and G. Korte (1980) Fine structure of granule cells and related interneurons (termed Golgi cells) in the cochlear nuclear complex of cat, rat and mouse. J. Neurocytol. $9: 537-570$

Oberdorfer, M.D., M.H. Parakkal, R.A Altschuler, and R.J. Wenthold (1987) Co-localization of GLY and GABA in the cochlear nucleus. Soc. Neurosci. Abstr. 13:544.

Oberdorfer, M.D., M.H. Parakkal, R.A. Altschuler, and R.J Wenthold (1988) Ultrastructural localization of GABA-immunoreactive terminals in the anteroventral cochlear nucleus of the guinea pig. Hear. Res. 33:229-238.

Oertel, D., and R.E. Wickesberg (1993) Glycinergic inhibition in the cochlear nuclei: Evidence for tuberculoventral neurons being glycinergic. In M. Merchan, J. Juiz, D. Godfrey, and E. Mugnaini (eds): The Mammalian Cochlear Nuclei: Organization and Function. New York: Plenum Press, pp. 225-238.

Oertel, D., and S.H. Wu 1 1989) Morphology and physiology of cells in slice preparations of the dorsal cochlear nucleus of mice. J. Comp. Neurol. $283: 228-247$

Osen, K.K., O.P. Ottersen. and J. Storm-Mathissen (1990) Colocalization of glycine-like and GABA-like immunoreactivities: A semiquantitative study of individual neurons in the dorsal cochlear nucleus. In O.P. Ottersen, J. Storm-Mathissen (eds): Glycine Neurotransmission. Chichester: J. Wiley and Sons, pp. 417-451.

Osen, K.K., D.E. Lopez, T.A. Slyngstad, O.P. Otterson, and J. StormMathisen (1991) GABA-like and glycine-like immunoreactivities of the cochlear root nucleus in rat. J. Neurocytol. 20:17-25.

Ostapoff, E.M., and D.K. Morest (1991) Synaptic organization of globular bushy cells in the ventral cochlear nucleus of the cat: A quantitative study. J. Comp. Neurol. 314:598-613.

Ostapoff E.M., D.K. Morest, and S.J. Potashner (1990) Uptake and retrograde transport of $\{3 \mathrm{H}\rangle \mathrm{GABA}$ from the cochlear nucleus to the superior olive in the guinea pig. J. Chem. Neuroanat. 3:285-295.

Ottersen, O.P., J. Storm-Mathisen, and P. Somogyi (1988) Colocalization of GLY-like and GABA like immunoreactvities in Golgi cell terminals in the rat cerebellum: A postembedding light and electron microscopic study. Brain Res. 45:342-353.

Ottersen, O.P., J. Storm-Mathissen, and J.H. Laake (1990) Cellular and subcellular localization of glycine studied by quantitative electron microseopic immunocytochemistry. In O.P. Ottersen, and J. Storm-Mathissen (eds): Glycine Neurotransmission. Chichester: J. Wiley and Sons, pp. 303-328.

Pappas, G.D., and S.G. Waxman (1972) Synaptic fine structure-morphological correlates of chemical and electrotonic transmission. In G.D. Pappas, and D.K. Purpura (eds): Structure and Function of Synapses. New York: Raven Press, pp. 1-44.

Peyret, D., M. Geffard, and J.M. Aran (1986) GABA-immunoreactivity in the primary nuclei of the auditory central nervous system. Hear. Res. 23:115-121.

Peyret, D., G. Campistron, M. Geffard, and J.M. Aran (1987) Glycine immunoreactivity in the brainstem auditory and vestibular nuclei of the guinea pig. Acta Otlaryngol. (Stockh.) 104:71-76.

Potashner, S.J., N. Lindberg, and D.K. Morest (1985) Uptake and release of GABA in the guinea pig cochlear nucleus after axotomy of cochlear and centrifugal fibers. J. Neurochem. 42:1135-1144.

Potashner, S.J., C.G. Benson, E.M. Ostapoff, N. Lindberg, and K. Morest (1993) Glycine and GABA: Transmitter candidates of projections descending to the cochlear nucleus. In M. Merchan, J. Juiz, D. Godfrey, and 
E. Mugnaini (eds): The Mammalian Cochlear Nuclei: Organization and Function. New York: Plenum Press, pp. 195-210.

Roberts R.C., and C.E. Ribak (1987) GABAergic neurons and axon terminals in the brainstem auditory nuclei of the gerbil. J. Comp. Neurol $258: 267-280$.

Saint Marie R.L., D.K. Morest, and C.J. Brandon (1989) The form and distribution of GABAergic synapses on the principal cell types of the ventral cochlear nucleus of the cat. Hear. Res. 42:97-112.

Saint Marie, R.L., C.G. Benson, E.M. Ostapoff, and D.K. Morest (1991) Glycine immunoreactive projections from the dorsal to the anteroventral cochlear nucleus. Hear. Res. 51:11-28.

Saint Marie, R.L., E.M. Ostapoff, C.G. Benson, D.K. Morest, and S.J Potashner (1993) Non-cochlear projections to the ventral cochlea nucleus: Are they mainly inhibitory? In M. Merchan, J. Juiz, D. Godfrey, and E. Mugnaini (eds): The Mammalian Cochlear Nuclei: Organization and Function. New York: Plenum Press, pp. 121-132.

Schwartz, A.M., and R.L. Gulley (1978) Non-primary afferents to the principal cells of the rostral anteroventral cochlear nucleus of the guinea pig. Am. J. Anat. 153:489-508.

Shiraishi. T., E. Senba, M. Tohyama, J.Y. Wu, T. Kubo, and T. Matsunaga 1985) Distribution and fine structure of neuronal elements containing glutamate decarboxylase in the rat cochlear nucleus. Brain Res. 347 183-187.

Smith, P.H., and W.S. Rhode (1985) Electron microscopic features of physiologically characterized, HRP-labeled fusiform cells in the cat dorsal cochlear nucleus. J. Comp. Neurol. 237:115-121.

Smith. P.H., and W.S. Rhode (1989) Structural and functional properties distinguish two types of multipolar cells in the ventral cocchlear nucleus. J. Comp. Neurol. 282:595-616.

Spangler, K.M., and W.B. Warr (1991) The Descending Auditory System. In R.A. Altschuler, R.P. Bobbin, B.M. Clopton, and D.W. Hoffman (eds): Neurobiology of Hearing, The Central Auditory System. New York Raven Press, pp. 27-46.

Staatz-Benson, C., and S.J. Potashner (1987) Uptake and release of GLY in the guinea pig cochlear nucleus. J. Neurochem. 49:128-137.

Staatz-Benson, C., and S.J. Potashner (1988) Uptake and release of GLY in the guinea pig cochlear nucleus after axotomy of afferent or centrifugal fibers. J. Neurochem. 51:370-379.

Thompson, G.C., A.M. Cortez, and D.M. Lam (1985) Localization of GABA immunoreactivity in the auditory brainstem of guinea pigs. Brain Res. 339:119-122

Tolbert, L.P., and D.K. Morest (1982) The neuronal architecture of the anteroventral cochlear nucleus of the cat in the region of the cochlear nerve root: Electron microscopy. Neuroscience 7:3053-3067.

Triller, A. F. Cluzeaud, and H. Korn (1987) Gamma-aminobutyric acidcontaining terminals can be apposed to glycine receptors at central synapses. J. Cell Biol. 104:947-956.

Triller, A., F. Cluzeaud, and T. Seitanidou (1990) Immunocytochemical localization of the glycine receptor. In O.P. Ottersen, J. StormMathissen (eds): Glycine Neurotransmission. Chichester: J. Wiley and Sons, pp. 83-110.

Triller, A.C., J. Sur, and H. Korn (1993a) Heteregoneous distribution of glycinergic and GABAergic afferents on an identified central neuron. J. Comp. Neurol. 338:83-96.

Triller. A.C., J. Sur, J. Storm-Mathissen, O.P. Ottersen, and H. Korn (1993b) Glycine and GABA coexist in the same presynaptic bouton of rat spinal cord. Eur. J. Neurosci. Suppl. 6:729.
Uchizono, K. (1965) Characteristics of excitatory and inhibitory synapses in the central nervous system of the cat. Nature 207:642-643.

Valdivia O. (1971) Methods of fixation and the morphology of synaptic vesicles. J. Comp. Neurol. 142:257-273.

Vetter, D.E., C. Cozzari, B.K. Hartman, and E. Mugnaini (1993) Choline acetyltransferase in the rat cochlear nuclei: Immunolocalization with a monoclonal antibody. In M. Merchan, J Juiz, D. Godfrey, and E. Mugnaini (eds): The Mammalian Cochlear Nuclei: Organization and Function. New York: Plenum Press, pp. 279-289.

Wenthold, R.J. (1987) Evidence for a glycinergic pathway connecting the two cochlear nuclei: An immunocytochemical and retrograde transport study Brain Res. 415:183-187.

Wenthold, R.J. (1991) Neurotransmitters of brainstem auditory nuclei. In R.A. Altschuler, R.P. Bobbin, B.M. Clopton, and D.W. Hoffman (eds) Neurobiology of Hearing, The Central Auditory System. New York: Raven Press, pp. 121-140.

Wenthold, R.J., and C. Hunter (1990) Immunocytochemistry of glycine and GABA receptors in the central auditory system. In O.P. Ottersen, and $J$ Storm-Mathissen (eds): Glycine Neurotransmission. Chichester: J. Wiley and Sons, pp. 391-416.

Wenthold, R.J., and M.R. Martin (1984) Neurotransmitters of the auditory nerve and central auditory system. In C. Berlin (ed): Hearing Science. San Diego: College Hill Press, pp. 341-369

Wenthold, R.J., J.M. Zempel, M.H. Parakkal, K.A. Reeks, and R.A. Altschuler (1986) Immunocytochemical localization of GABA in the cochlear nucleus of the guinea pig. Brain Res. 380(1):7-18.

Wenthold, R.J., D. Huie, R.A. Altschuler, and K.A. Reeks (1987) GLY immunoreactivity localized in the cochlear nucleus and superior olivary complex. Neuroscience 22:897-912.

Wenthold, R.J., M.H. Parakkal, M.D. Oberdorfer, and R.A. Altschuler (1988) Glycine receptor immunoreactivity in the ventral cochlear nucleus of the guinea pig. J. Comp. Neurol. 276:423-435.

Werman, R. (1980) GABA modulates the glycine-receptor interaction in Mauthner cell allosterically. In U.Z. Littauer, Y. Dudai, I. Silman, V.I Teichberg, and Z.Vogel (eds): Transmitters and their Receptors. Chichester: J. Wiley and Sons, pp. 393-404

Wickesberg, R.E., and D. Oertel (1988) Tonotopic projection from the dorsal to the anteroventral cochlear nucleus of mice. J. Comp. Neurol. 268 389-399

Wickesberg, R.E., and D. Oertel (1991) Tuberculoventral neurons project to the multipolar cell area but not to the octopus cell area of the posteroventral cochlear nucleus. J. Comp. Neurol. 313:457-468.

Wickesberg, R.E., and D. Oertel (1993) Intrinsic connection in the cochlear nuclear complex studied in vitro and in vivo. In M. Merchan, J.Juiz, D Godfrey, and E. Mugnaini (eds): The Mammalian Cochlear Nuclei: Organization and Function. New York: Plenum Press, pp. 77-90.

Wouterlood, F.G., and E. Mugnaini (1984) Cartwheel neurons of the dorsa cochlear nucleus: A Golgi-electron microscopic study in rat. J. Comp Neurol. 227:136-157.

Wouterlood, F.G., E. Mugnaini, K.K. Osen, and A.L. Dahl (1984) Stellate neurons in rat dorsal cochlear nucleus studied with combined Golg impregnation and electron microscopy: Synaptic connections and mutua. coupling by gap junctions. J. Neurocytol. 13:639-664.

Wu, S.H., and D. Oertel (1986) Inhibitory circuitry in the ventral cochleat nucleus is probably mediated by glycine. J. Neurosci. 6:2691-2706. 